\title{
A NEW SERIOUS GAME FOR CHILDREN TO EXPLAIN INNOVATION AND ENHANCE CREATIVITY
}

\author{
Eloïse BOYET, Lucile COUTURE, Louis GRANIER, Thomas ROUDES, Agathe VIDAL, \\ Nicolas MARANZANA and Camille JEAN \\ Arts et Metiers Institute of Technology, LCPI, HESAM Université, F-75013 Paris, France
}

\begin{abstract}
Serious games, educational games that aim the development of a competence in a ludic way, for children are soaring on the market. Nonetheless, very few tackles the subjects of innovation and creativity. The purpose of this article is to present a new serious game to address this point. In fact, a project was carried out two years ago, resulting in a serious game called "Lino has an idea!", which had interesting approaches. The team had registered feedback on their game from teachers and students from third and fifth grade. The feedback together with our ideas lead us to improve the game.

The purpose of our serious game is to create an immersive universe where children can learn how an idea can be developed and become a project. The different steps of the innovation process will be based on the different stages of innovation. The serious part of this game includes a time to brainstorm around the methods of creativity used in the innovation field. One of our goals is also to design the game more immersive for children, so they can really be invested in it and enjoy playing.

We conducted a case study with two classes of children aged 8-9 and 10-11 years old. In this article, we present the concept of our serious game and the results and conclusion of that case study.
\end{abstract}

Keywords: Innovation, creativity, serious game, children, immersive universe

\section{INTRODUCTION}

Creativity and innovation are real assets and skills sought after in the world of industry and work. While some are innate, innovation techniques are skills to be acquired, and the sooner the better. However, educational games for children are currently underdeveloped [1]. In this article, we will present our process of creating and designing our game, as well as a review of its testing in classrooms.

Section 2 of the article will be devoted to a benchmarking study of educational games. Section 3 will develop the objectives of the game, the gameplay imagined, and the physical realization of the game. The classroom experience and the debrief of this experimentation will be seen in sections 4 and 5 with the possibilities of evolution. Finally, in the concluding section, we will discuss the perspectives and recommendations following the creation of the game.

\section{BACKGROUND}

Lots of games for children are developing creativity [2]. But there are closer to an individual awakening of creativity than to a real educative game giving the bases of the innovation concept in team. Although serious games are booming in higher education and companies, there are used very little in primary school, middle school, and high school (Figure 1) while these are ages when brains are developing quickly and are very receptive to these kinds of activities. And, according to our research [1], if serious games are underdeveloped in primary school, serious games dealing with innovation and teamwork are absent. 




Figure 1. Taxonomy of different serious game (from [1])

In order to benefit teaching and learning, one of the most interesting ways is to enhance the interactive dynamic of games [3-5]. As most traditional forms of teaching cannot attract and please children, adapted principles, structures, and mechanics, need to be designed. According to Educause [6] "gamebased learning platforms can create an engaging dynamic that inspires students to develop competencies and skills as they focus on the activities of the game."

\section{RULES AND GAMEPLAY}

For the design of our game, we followed the DICE generic model in 4 steps: Define, Imagine, Create and Evaluate [7]. Based on the results of the previous game "Lino has an idea!" [8], this part presents the updated objectives, rules, motivation tools used and universe.

\subsection{The objectives}

The game's aims are educational and playful games designed for primary school classes. The serious game is dedicated to give them the first keys of the creative process of innovation: the product's constraints, the steps, some creativity methods, etc. The other objective is to give them teamwork tools and autonomy.

\subsection{The rules}

Before the start of the game, children form randomly groups of four to seven. Then each child chooses a role in the team, to facilitate team efficiency (Table 1).

Table 1. Roles in the game

\begin{tabular}{|c|c|c|}
\hline Role & Animal & Description \\
\hline Guardian of the word & Penguin & Manage the speed distribution with the talking stick \\
\hline Master of the time & Rabbit & Manage the time and the rhythm \\
\hline Goalkeeper & Squirrel & Keep the objectives in mind and refocus the discussion \\
\hline Secretary & Owl & Take care of the written trace \\
\hline Designer & Deer & Take care of the drawn trace \\
\hline Presenter & Bear & Present the final product in front of the class \\
\hline Reporter & Giraffe & Explain the team progress to the supervisor \\
\hline
\end{tabular}


The game is constituted of seven steps which represent the seven steps of the innovation process (Table 2).

Table 2. Game rules

\begin{tabular}{|c|c|c|}
\hline Steps & Explanation & Time \\
\hline $\begin{array}{l}\text { Definition of } \\
\text { the need }\end{array}$ & The group throw the dice and agree on a product idea & $10 \min$ \\
\hline $\begin{array}{l}\text { Choice of } \\
\text { innovation }\end{array}$ & $\begin{array}{c}\text { Each member proposes his vision, and the group finally chooses a } \\
\text { product }\end{array}$ & $10 \mathrm{~min}$ \\
\hline $\begin{array}{l}\text { Method of } \\
\text { creativity }\end{array}$ & The group is given a creativity method and put it in practice & $20 \mathrm{~min}$ \\
\hline Recreation & $\begin{array}{l}\text { The children go to the schoolyard to be more efficient for the } \\
\text { endgame. They can use the schoolyard to exchange between groups. }\end{array}$ & $15 \mathrm{~min}$ \\
\hline $\begin{array}{l}\text { Convergence } \\
\text { of ideas }\end{array}$ & $\begin{array}{c}\text { The group draws up a list of advantages and disadvantages and } \\
\text { makes the final modifications }\end{array}$ & $10 \mathrm{~min}$ \\
\hline Presentation & $\begin{array}{l}\text { The group prepares a quick presentation and presents the object to } \\
\text { the class }\end{array}$ & $15 \mathrm{~min}$ \\
\hline Feedback & $\begin{array}{l}\text { The children vote for each category and the teacher presents the } \\
\text { nominees. Then the children close their eyes, and the leader asks } \\
\text { them some questions about how efficient their group was and how } \\
\text { did it work }\end{array}$ & $10 \mathrm{~min}$ \\
\hline
\end{tabular}

\subsection{The motivational tools and the universe}

The game is dedicated to children. So playful and motivational tools are quite essential [9]. That is why we used the Lino narrative frame. Lino is a young fox who dreams of a product and spends the following day shaping his product idea with his friends, teachers, and parents. His school day rhythms the game. For the aesthetic and attractive aspect, we used a graphical charter adapted, with cute animals (Figure 2).



Figure 2. Game universe

We also added some entertaining accessories: three dices to represent Lino's dream (technological field, type of object and a main characteristic) and a wheel of tricks to choose a creativity method. Finally, in order to motivate all groups, we added a nomination at the end permitting participants to vote for the other products in four categories: Useful, Funny, Original and Aesthetic.

\subsection{Game board}

To create a board for our game that would be both playful and interactive for the children, and also, that shows the different steps of Lino's day in school, the first configuration was « classic » with cases. Nevertheless, the drawback of this configuration is that we do not see a real linear evolution of the 
innovation, but more of a cycle as if after one round, the players had to start another round. The objective is to show the path of thought and action to develop an innovation, so the image of a cycle is not appropriate. There must be a clear distinction between the beginning, i.e., the idea, and the end, i.e., the final presentation of the innovation. Thus, the board was conceived with a spiral shape, like a snail, with the beginning at the extremity and the end in the centre (Figure 3 ).

Playing with the spiral allows to create a board with steps at different levels, creating a real path through innovation. Moreover, the board is separated into two pieces: one piece to hold the cards, the dice, and other accessories, and one piece with the spiral divided in steps. This enables an interaction with the board from the beginning because children have to put together their spiral board like a puzzle.
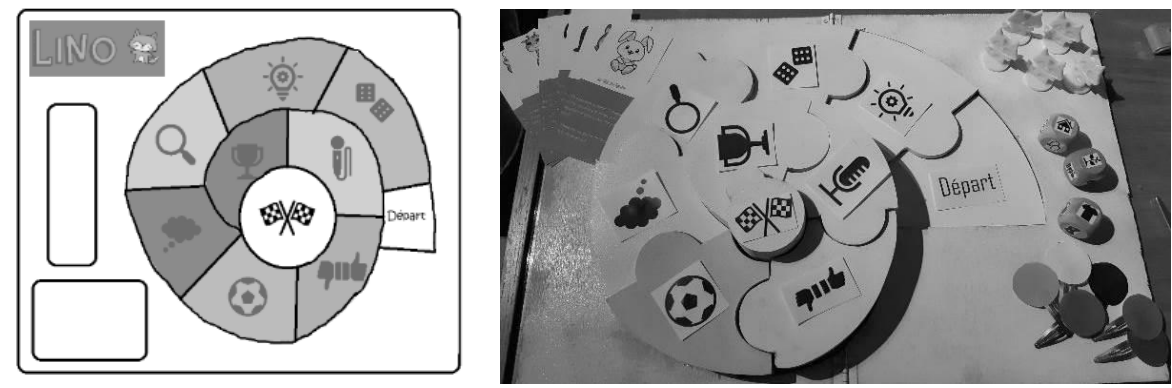

Figure 3. Game board prototype

For the need of the experiment, a first prototype of the board with different techniques was built either by cutting wood and with 3D-printing. On a larger scale, to sell the game, we would have to use materials and techniques that are both solid and cheap. The Lino pieces were 3D-printed, and images were glued on the wood dice.

\section{CASE STUDY}

A case study, taking in account usability [10] and game engagement [11], was managed twice in January 2021 , in a primary school in Le Pecq, a city in France near Paris. The public targeted are children from 8 to 10 years old, so the game was tested in two classes, one of 28 pupils in third grade ( 8 years old) and one of 20 pupils in fifth grade ( 10 years old) (Table 3$)$. In the first case, children were grouped randomly by 5 and in the second, they were grouped by 7 .

Table 3. Gender repartition in the classes

\begin{tabular}{|l|c|c|}
\hline & GIRLS & BOYS \\
\hline Third grade & 12 & 17 \\
\hline Fifth grade & 8 & 12 \\
\hline
\end{tabular}
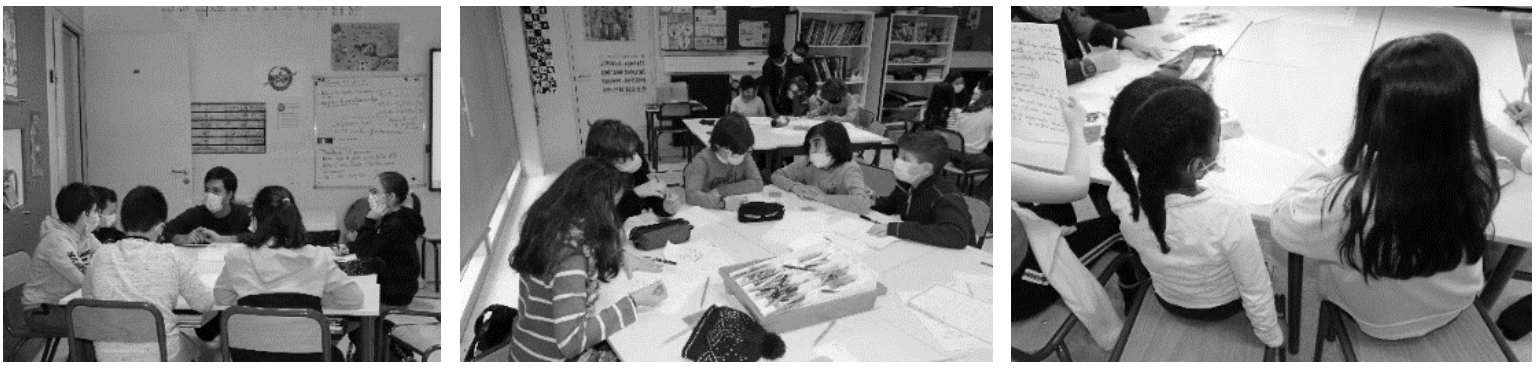

Figure 4. Photos taken during the case study

The class was organized in work islands to foster teamwork (Figure 4). The process presented Figure 5 was used. The designers' team ( 5 members) supervised the game and the children by explaining the rules and answering their questions. Both classes were free to create whatever they wanted, regardless of feasibility. In the third-grade class, one supervisor was assigned to one group. 

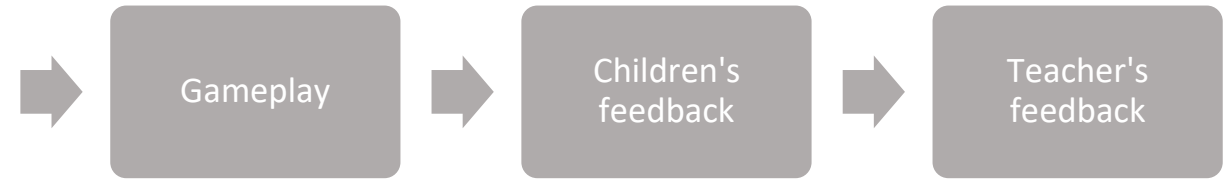

Figure 5. Steps of the case study

At the end of the game, children took a satisfaction survey of four questions, based on a 3 steps Likert scale made of four emoticon faces, from $\odot$ to $\Theta$, which they coloured depending on the state they were feeling (Table 4).

Table 4. Questions and mean of the answers to the survey

\begin{tabular}{|c|c|c|}
\hline QUESTIONS & $\begin{array}{c}3^{\mathrm{RD}} \text { GRADE } \\
/ 3\end{array}$ & $\begin{array}{c}5^{\mathrm{TH}} \text { GRADE } \\
/ 3\end{array}$ \\
\hline Did you find the game fun? & 2,69 & 2,85 \\
\hline Did you understand all the game rules? & 2,15 & 2,58 \\
\hline Did you understand the "trick" given by lino's teacher? & 2,31 & 2,25 \\
\hline Do you like the design of the game? & 2,70 & 2,74 \\
\hline TOTAL & 2,41 & 2,60 \\
\hline
\end{tabular}

Then, the class was asked orally three qualitative questions so children could react to what has been said: 1. After this game, how would you define innovation? // 2 . What did you like the most in the game? // 3. What did you unlike the most? // 4. What would you add in the game? After the game, children had a clearer vision of innovation. Very few children reported something they did not like; they were enthusiastic, as shown in the table above, and liked the team play.

The designers' team also registered the feedback of the teachers to determine the affordability and the relevancy of the game. Teachers reported the capacity of the game to foster children creativity and enhance teamwork skills. However, they questioned the physical game board, instead of a digital one.

\section{DISCUSSIONS AND PERSPECTIVES}

This experience was globally satisfactory for both classes (third and fifth graders) and their teachers. First, we observed the children. Both classes were highly motivated and deeply involved in the game. The fifth graders were globally calmer than the third graders. The fifth graders listened more to each other and were more able to respect the roles they were assigned to. During the game, we noticed that the storytelling about Lino's day had more impact on the third graders than on the fifth graders. This storytelling phase allowed the third graders to calm down and refocus on the activity. For the fifth graders, the storytelling did not change their way of playing. Ideally, the storytelling format should be adapted to the age of the pupils, so that Lino's story can be shared effectively for all age groups. We have also noticed that children in the third and fifth grades progressed very quickly in developing their innovation, making the intermediate stages of creation obsolete. A way should be found to "slow down" the pace of the children, by allowing them to take advantage of all the tricks of the game in order to create their own innovation.

In a second step, we collected the students' opinions and their ideas of improvement. The fifth-grade students would have liked to experience storytelling in video format: this would have provided real added value by capturing their attention. The third graders would have liked to move more in the classroom, for example by allowing each member of the group to stand up in order to move his/her team's pawn on the game board (during our experiment, only one child from each team was designated to perform this task). Children in both classes would also have appreciated having a real "talking stick". The third graders particularly liked the dice step, they also loved drawing. The fifth graders preferred the oral presentation step in front of the class. They were also very responsive to the design of the game board and the role cards.

From the teachers' point of view, the game was very enriching for both classes and allowed the children to get used to teamwork. Nevertheless, a teacher cannot currently set up this game alone: the presence of several adults is necessary to guide the children. The teachers also pointed out to us that the design 
of the dice was not optimal for the children. Indeed, the drawings on the sides of the dice lock the children into very specific ideas. Replacing the drawings with words (for example, replacing the drawing of the rocket with the word "space") would allow children to expand the range of possible ideas.

Teachers are delighted with the experience and would be able to buy a copy of the serious game for their school.

\section{CONCLUSIONS}

As we have seen in the article, children need to develop their creative and innovative skills as soon as possible. After defining the rules and the gameplay, we designed the game board as well as the different cards and sheets useful for feedback. We then tested it in a school: the children had fun and wanted to start playing again.

This educational game allows children to work in groups, which is not always possible in class according to their teachers, and also to discover new methods of creativity. During the game, the children must find ideas, improve them, and decide together on their final innovation.

For the next steps of the project, a study has to be conducted to improve the game board and accessories accordingly to the children and teacher feedback.

\section{REFERENCES}

[1] Cortes Sobrino A., Bertrand M., Di Domenico E., Jean, C., and Maranzana N. (2017). Educational games for design and innovation: Proposition of a new taxonomy to identify perspectives of development. In DS 87-9 Proceedings of the 21st International Conference on Engineering Design. Vol 9: Design Education, Vancouver, Canada.

[2] Ma Y. (2021). Design of serious games for teaching industrial engineering methodologies: A design process based on $V$-model and an application in innovation engineering, $\mathrm{PhD}$ Thesis, CentraleSupélec, Université Paris-Saclay.

[3] Roth S., Schneckenberg D.and Tsai C. W. (2015). The ludic drive as innovation driver: Introduction to the gamification of innovation. Creativity and Innovation Management, 24(2), 300-306.

[4] Breuer J. and Bente, G. (2010). Why so serious? On the relation of serious games and learning. Journal for Computer Game Culture, 4(1), 7-24.

[5] Nicholson S. (2015). A recipe for meaningful gamification. In: Gamification in education and business. Springer, Cham, 1-20.

[6] Educause Learning Initiative. (2014). 7 Things You Should Know About Games and Learning.

[7] Djaouti D. (2020) DICE: A Generic Model for the Design Process of Serious Games. International Journal of Game-Based Learning, 10 (2), 39-53.

[8] Libe C., Grenouillat A., Lagoutte J., Jean C. and Maranzana, N. (2020). Creativity and innovation for children: presentation and first experiment of new (serious) game. In DS 104 Proceedings of the 22nd International Conference on Engineering and Product Design Education, VIA Design, VIA University Herning, Denmark.

[9] Kafai Y. (1994). Minds in Play: Computer Game Design as A Context for Children's Learning. Routledge.

[10] Nielsen J. (1994). Usability engineering. Morgan Kaufmann.

[11] Whittonn N. (2011). Game Engagement Theory and Adult Learning, Simulation and Gaming, 42(5), 596-609. 